I consider to be the best of all mouth gags) a little electric light. This is so arranged that it can be fitted to either arm of the gag and turned to the right or left side as required, and it enables the surgeon to get a good view of the whole of the inside of the mouth. The light is supplied by the "Davon" battery, which is an extremely handy and portable form of battery, and which lasts about ten hours. Being removeable it enables the whole of the gag to be sterilised by boiling. The accompanying illustration shows the main features of the gag as thus modified, and I need only add that Messrs. Davidson and Co., of 29, Great Portland-street, W., having taken the greatest pains, have been most successful in carrying out all the suggestions I have made to them in regard to it.

Wimpole-street, $\mathrm{W}$.

Cecil H. Leaf, F.R.C.S. Eng.

\section{A RUBBER CUP PESSARY.}

THE figure illustrates a very useful pessary, a rubber cup with vulcanite stem which Messis. Allen and Hanburys have made for me. It is more easily introduced than the vulcanite cup and it gives more to the movements of the

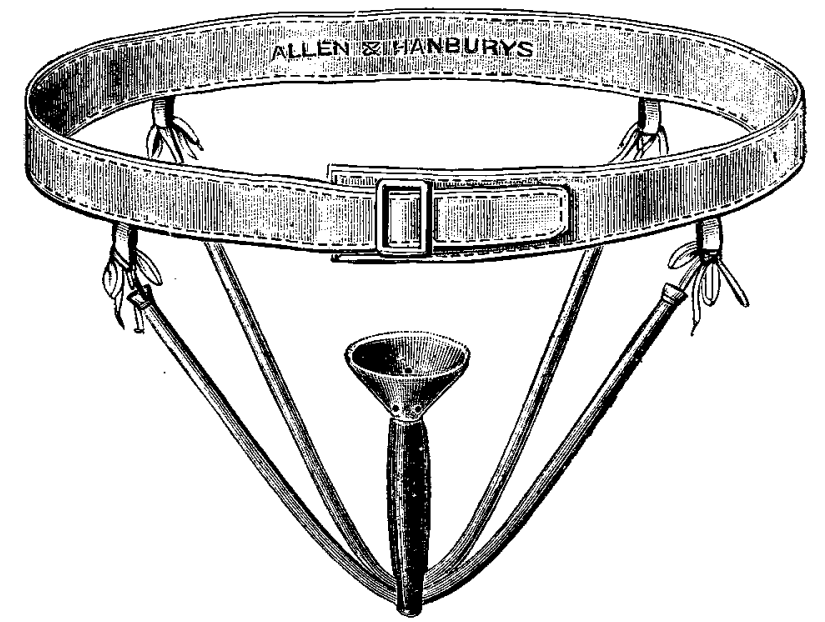

body. The all-rubber instruments are apt to double up with a heavy uterus. I have used these pessaries for some years and have found them most satisfactory.

J. H. Dudgeon, L.R.C.P. \& S. Edin.,

Honorary Surgeon, Workington Infirmary, Cumberland.

\section{Dooking JBack.}

\section{FROM}

THE LANCET, SATURDAY, Feb. 11th, 1832.

WESTMINSTER MEDICAL SOCIETY.

Saturday, February 4, 1832.

Dr. SIGMOND in the Chair.

\section{CLASTIC ANATOMY.}

PROPOSALS TO TEACH ANATOMY BY MIEANS OF SOLID PIECES CAPABLE OF BEING MOUNTED AND DISMOUNTED.

THE attendance at this Society is very variable, sometimes flagging for two or three successive evenings, when the room of meeting again becomes crowiled with members and visitors. The assemblage to-night was very numerous : the "Anatomy Petitions" lay on the table for signature, and might have been the cause of attraction. Whatever was the reason, however, few could have departed displeased with the evening's recreation. On entering the room we found preparations making for displaying to the Society a work of art, the ingenious inventor and constructor of which, Dr. Auzoux, was present. This work of art was an ARTIFICIAL
HUMAN BODY, which being now brought forward and placed upon its frame, attracted the eager attention of those present.

Mr. Costello, as a friend of Dr. Auzonx, introduced the "subject" with some appropriate remarks.

Amongst the many scientific gentlemen whose minds had been directed to the furtherance of anatomical studies by the construction of artificial bodies, Dr. Auzoux was one who from his youth had seriously entertained the design, which was now brought to so satisfactory a conclusion. It was a singular fact, that the original accomplishers of two grand features in modern surgical improvement, Dr. Auzoux and M. Civiale, were fellow-students, intimate friends, each of whom, however, looked upon the other's peculiar scientific penchant as an illusion incapable of realization. After many years of laborious trials and patient investigation, and after presenting to the world two or three specimens, Dr. Auzoux had at length produced the present, which was so accurate in its bearings, and so comprehensive in its details, as to render it of the utmost value to the student and the practitioner, and deserving the attention of the legislature, especially at a time when the question of anatomical study was beset with so many difficulties.

Dr. Auzoux has taken for his model the frame of an athletic man of tolerable height, the muscles being fully and beautifully developed. The position is well chosen, and, the feet being fixed firmly on a wooden frame work, admits of the manipulation requisite for the study of the figure. The integuments are absent, and the first layer of muscles is exposed to view as if cleanly dissected for a "demonstra. tion." These however are removed separately with the greatest facility, so as to reveal, layer after layer, the various aspects of the parts-muscles, tendons, bones, \&c., being coloured after nature. To the different members are attached labels having referense to a synoptical table, bearing the name of the organ, and pointing out the extremity by which the displacement is effected. It afforded us great pleasure to observe the facility with which the disicetron might be accomplished, and in some parts the tout ensemble of the "region" was striking for fidelity of imitation, and, as far as we could observe, perfect accuracy of execution. As instances, the inguinal, abdominal, and cerrical regions, may be selected as excellent, whilst the view of the posterior parietes of the chest, the internal structure of the heart, kidney, \&cc., deserve similar commendation. The textures of the organs have been well imitated, so as indeed not to be mistaken; but in this respect, we think, a much nearer approach may be made to the bona-fide structures of the human body. Not a small advantage of this invention is the durability of the material of which the model is composed. Admitting at first of being moulded into any shape, it acquires the hardness of wood, so as to render the handling of the parts totally free from danger of injury; and the whole figure is constructed of the same composition. Some time was taken up in the exhibitions repeatedly eliciting the warm admiration of the members, which, in conclusion, was testified by an unanimous vote of thanks to Dr. Auzoux.

Dr. SIGMOND, therefore, in the name of the Society, returned thanks to the talented foreigner, who requested $\mathrm{Mr}$. Costello to express his acknowledgments.

The different pieces of the model require but a few minutes to put them together again, although the parts amount, we believe, to one hundred and twenty-nine.

Dr. Auzoux, in reply to a member, stated that the price of such a model was 3000 francs, or $125 l$.

Dr. BLICKE thought it incorrect to designate this invention as "new." He had seen the same kind of thing in wax many years ago in Germany and Italy; but (in answer to a query) such preparations were kept in glass cases, though they might be handled on particular request.

A Gentleman observed that he had also seen similar models in Bologna, but by no means so perfect, and in wax.

[Dr. Auzoux's model has just been purchased for the King's College. $\left.{ }^{1}\right]$

1 In THE LANCET of May 29th, 1909, p. 1551, an excerpt under the heading of "Looking Back" relating to other "anatomical and obstetric machinery" contained also a short reference praising the anatomical machines invented by M. Auzoux, further particulars of which are now given in the current number of THE LANCET select 